\title{
The use of the accident and emergency department
}

\author{
P. A. DRISCOLL, C. A. VINCENT \& M. WILKINSON \\ Accident and Emergency Department, University College Hospital, London, England
}

\section{SUMMARY}

Many studies have shown that a high proportion of patients attending accident and emergency (A\&E) departments have only trivial or non-urgent complaints. A\&E staff treat these inappropriate attenders while recognizing that this detracts from the care given to more serious cases. Dwindling resources and higher attendances make it a matter of necessity that inappropriate attenders be treated by general practioners or equivalent primary care services.

In this study, the authors examined the feasibility of methods of reducing inappropriate attendance. The authors investigated patients' ability to accurately assess the urgency of their condition and, hence, their need for A\&E services. The authors concluded that there is probably no practical way of reducing inappropriate attendance that does not involve risk to a proportion of patients. The possibility of extending the role of the $A \& E$ department to provide more general primary care is discussed.

\section{INTRODUCTION}

Farmer \& Chambers (1982) reported a survey showing that $43 \%$ of patients attending the Accident and Emergency (A\&E) Department at University College Hospital, London, England, were inappropriate attenders, in that they were judged as being more suitably seen by a general practitioner (GP). Estimates of a number of similar surveys that they reviewed varied from $35-75 \%$. Comparison of surveys is difficult because of the different definitions of inappropriate attendance that have been employed: for example, 'clinical urgency' and 'treatable by a GP.' It is clear though, that a large proportion of people attending $A \& E$ do not require the specialist services that the departments provide.

Correspondence: $\mathrm{Mr}$ P. A. Driscoll, Accident and Emergency Department, University College Hospital, Grafton Way, London NW1, England. 
In 1976, the total number of patients attending A\&E departments exceeded the tot number of new cases in all other outpatient departments combined. Since that time surveys have shown a progressive rise in the number of attendances (Wilson, 1980 This has been coupled with a decline in resources throughout the National Healt Service. Departments are hard pressed, and patients with minor or trivial complain add an extra burden. However, in spite of numerous studies (for example, Farmer \& Chambers, 1982; Bradbury \& Lewis, 1982) describing and quantifying the extent of inappropriate attendance no agreed policy has yet emerged to deal with this problemp

Any effective policy decision on the proper function of an A\&E department has to bo communicated to the general public. At the moment, patients are asked only to attend their condition is urgent. One reason for the ineffectiveness of this request may be tha patients are not able to judge the urgency of their condition. There also needs to be $\vec{a}$ way of dealing with inappropriate attenders who still come to the department. The mos plausible solution is a triage system run by an experienced nurse, where patients wit? minor complaints can be screened out and directed elsewhere for treatment. Howeve the nurses would need clear guidelines which have the absolute backing of seniof medical staff. Earlier studies (for example, Farmer \& Chambers, 1982) have commented on the high proportion of inappropriate attenders who have conditions over a day old?. Duration of condition would, therefore, seem a possible criterion for use in a triage system.

Therefore, this study had the following aims:

(1) to determine the current proportion of inappropriate attenders and to compare with earlier assessments;

(2) to assess the accuracy of patients' assessment of the urgency of their condition a hence, its suitablity as an indicator of need of A\&E services; and

(3) to assess the usefulness of duration of condition as a criterion of appropriat: attendance for use in a triage system.

\section{METHOD}

All patients attending the A\&E department at University College Hospital in one wee were studied. The method of study and analysis of data parallelled that of the earlietr. study by Famer \& Chambers (1982), except that data were collected by A\&E staff rather than by a research team. The authors recorded GP registration and prior contaco duration of condition, urgency of condition in the patient's eyes and appropriateness of attendance as judged by the casualty officer. It is difficult to define appropriate attendance and the judgements made by the medical staff will inevitably have subjective element. The casualty officers were asked to rate as inappropriate only those cases who could clearly have been seen by a GP or who required no medical attention a all. We consider that this criterion gives a conservative estimate of inappropriate attendance. 


\section{RESULTS}

\section{$G P$ registration and contact}

Eighty per cent of patients were registered with a GP and, if they had a non-urgent condition, could presumably have contacted him or her. However, only $17 \%$ of patients did so and, of these, only half brought a letter from the GP to the A\&E Department.

\section{Casualty officers' judgements of appropriateness of attendance}

Data was collected on 835 patients. Of these, $460(55 \%)$ were judged as appropriate for A\&E. Two hundred and ninety-two $(35 \%)$ patients were judged as being clearly more appropriate for the GP and a further $42(5 \%)$ were judged as not needing the attention of any medical practitioner. In the remaining $5 \%$ of patients, the casualty officer was uncertain of the most suitable place of treatment. In all, $40 \%$ of patients were judged as being inappropriate to the A\&E department, being either GP cases or not needing any doctor.

Table 1 Degree of urgency

\begin{tabular}{lccccc}
\hline & \multicolumn{5}{c}{ Casualty officer's assessment } \\
\cline { 2 - 6 } $\begin{array}{l}\text { Patient's } \\
\text { assessment }\end{array}$ & $\begin{array}{c}\text { Accident and } \\
\text { emergency }\end{array}$ & GP & $\begin{array}{c}\text { No attention } \\
\text { warranted }\end{array}$ & Uncertain & Total \\
\hline Urgent & $41 \%(342)$ & $21 \%(175)$ & $3 \%(25)$ & $3 \%(25)$ & $68 \%(567)$ \\
Non-urgent & $14 \%(117)$ & $14 \%(117)$ & $2 \%(17)$ & $2 \%(17)$ & $32 \%(268)$ \\
& $55 \%(459)$ & $35 \%(292)$ & $5 \%(42)$ & $5 \%(42)$ & $100 \%(835)$ \\
\hline
\end{tabular}

Patients' assessment of the urgency of their condition

Patients' assessment of their condition does not correspond well with casualty officers' judgement of their need for A\&E services. If it did, then patients who considered their condition urgent would be $A \& E$ appropriate and those who assessed their condition as non-urgent would be GP appropriate. However, $21 \%$ of all patients who thought their condition urgent in fact required GP services and, conversely, $14 \%$ of patients who considered their condition non-urgent needed $A \& E$ services.

\section{Duration of condition}

Table 2 Time to presentation

\begin{tabular}{lccccr}
\hline Time & $\begin{array}{c}\text { Accident and } \\
\text { emergency }\end{array}$ & GP & $\begin{array}{c}\text { No attention } \\
\text { warranted }\end{array}$ & Uncertain & Total \\
\hline$<24 \mathrm{~h}$ & $44 \%(367)$ & $12 \%(100)$ & $4 \%(33)$ & $2 \%(17)$ & $62 \%(517)$ \\
$>24 \mathrm{~h}$ & $11 \%(92)$ & $23 \%(192)$ & $2 \%(17)$ & $2 \%(17)$ & $38 \%(318)$ \\
& $55 \%(459)$ & $35 \%(292)$ & $6 \%(50)$ & $4 \%(34)$ & $100 \%(835)$ \\
\hline
\end{tabular}


Thirty-eight per cent of patients attended A\&E with conditions of greater than $24 \mathrm{H}$ duration. A proportion of these (11\% of all patients) still required A\&E services. 通 duration of condition had been used as a criterion for appropriate attendance, then thes patients would have been incorrectly turned away. Furthermore, a large group of inappropriate attenders remains in those with conditions of less than 24-h duration some needing a GP (12\% of total) and some requiring no attention (4\%).

\section{DISCUSSION}

There has been little change in the proportion of inappropriate attenders to the $\mathrm{A} \& \mathrm{E}$ department of University College Hospital: $43 \%$ in 1982 and $40 \%$ in 1986. All of these patients could have seen their GP: our definition of inappropriate attendance.

Patients attend A\&E rather than their GP's surgery for a variety of reasons. AD proportion $(20 \%$ in our study) are simply not registered. Farmer \& Chambers (1982) found that the most commonly given reasons for not attempting to contact the GP wers the availability of services and seeing the $A \& E$ department as the appropriate place of treatment (for over $50 \%$ of attenders, of course, it is the appropriate place). Difficulty ir getting an appointment with a GP is certainly a factor in central London, though proportion of patients are simply unwilling to wait for an appointment (Bradbury \& Lewis, 1982) and a few patients come simply for a second opinion. Some inappropriate্ attenders are sent by the GPs themselves, often without seeing the patient. A\&E can used simply to obtain blood samples or ECGs, or as a way of bypassing the outpatio appointment system. Some changes in GP services, in London, at least, are certaint required if only urgent conditions are to be seen in A\&E. As Calman (1979) points outo 'If the public is to be educated to use accident and emergency appropriately, they nee $\stackrel{\mathbb{P}}{2}$ to be convinced that alternative sources of medical treatment are readily available. $\overrightarrow{0}$ Exactly what is considered appropriate attendance will vary from one department to another. The role of $A \& E$ in a particular community must depend to some extent on the range of other medical services and the needs of the local community. Departments irm inner city areas, for instance, are likely to have a somewhat different function to rurat departments.

Whatever the availability of GP services, patients with minor conditions will continue to attend A\&E. There are basically two ways of approaching this problem: one is te place restrictions on the use of the A\&E department, and the other is to broaden the role of $A \& E$ and accept that dealing with minor, non-urgent conditions is an inevitable and acceptable part of the department's work. The authors will first consider the possibility of restrictions.

The results show that asking patients to attend $A \& E$ only with urgent conditions is ineffective. Firstly, many patients attend with conditions they admit are not urgent and secondly, their assessment of the urgency of their condition is not a good indicator op their need for emergency services. It is possible that a clearer statement of the department's function could be conveyed to the public, but there is no guarantee thate they would respect it. (An educational campaign by the DHSS had no effect on the number of inappropriate attenders.) Patients are satisfied with the treatment the 
receive in A\&E and are, therefore, encouraged to return (Bradbury \& Lewis, 1982). It is equally difficult, and time consuming, to screen out inappropriate attenders once they reach the department. It has been suggested that a triage system might be implemented but that guidelines for its implementation would be needed, in particular, criteria for appropriate and inappropriate attendance. The authors have shown that a possible criterion, duration of condition, does not successfully discriminate between appropriate and inappropriate attenders. Obviously, other criteria or combinations of criteria could be employed, but we suspect that all would be found inadequate, essentially because of the great variability of people and problems that present in $A \& E$.

It is clearly very difficult to reduce inappropriate attendance and it is not necessarily desirable. The other option is to expand the role of $A \& E$ to accommodate all the patients who attend. It might be argued that, if patients prefer, for whatever reason, to use the services of $A \& E$ rather than those of their GP, then they are perfectly entitled to do so (it is certainly proving difficult to stop them). The aim of any primary care outlet is surely to provide the services required by the patients. There is no reason why the A\&E department should not provide such services if it were adequately staffed and had sufficient resources. At present, however, it provides the additional service without the resources, which places a severe burden on the staff. If $A \& E$ departments are to provide GP services, then they need to be funded accordingly. The additional financial support could come from the redistribution of resources currently allocated to the GP services. Given that, in $40 \%$ of attenders, $A \& E$ departments in Inner London are providing services that the GPs are paid to perform, this does not seem entirely unreasonable.

The authors do not pretend to have a simple answer to the problem of inappropriate attendance. They do, however, suggest that finding a solution is now critical, at least in Greater London. Departments may have no option but to begin turning patients away in order to have time to deal with more serious problems. Any system that involves turning patients away is difficult to implement and is bound to involve some risk. For these reasons, and because of patient demand, the authors tend to favour expanding $A \& E$ and providing a GP service as an adjunct to the department's specific role, provided resources for this could be obtained.

\section{ACKNOWLEDGEMENTS}

C. A. Vincent is supported on a grant from the Medical Protection Society for a project on 'Avoidable Mishaps in Medicine' under the direction of Professor R. J. Audley. The opinions expressed, however, are those of the authors.

The authors would like to thank Dr H. Baderman for permission to conduct the study.

\section{REFERENCES}

Bradbury R. \& Lewis B. R. (1982) North Western regional study of Accident and Emergency services. Department of Management Services, University of Manchester. 
Calman M. (1979) Pathways to the Accident and Emergency Department. Centre for Research in the Socia Sciences, University of Kent.

Farmer R. D. T. \& Chambers J. S. (1982) The relationship between the uses of an Accident and Emergency

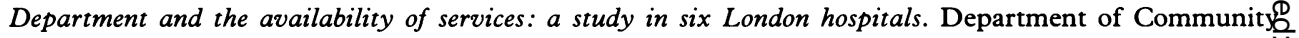
Medicine, Westminster Medical School.

Wilson D. H. (1980) The development of accident and emergency medicine. Community Medicine 2, 28-35

Received 25 September 1986; accepted 29 fanuary 1987 